\title{
Simulation Research on Solder Joint Residual Strain Energy of Au80/Sn20 Eutectic Soldering GaAs Chip
}

\author{
Yajun Liu, Zhaohua Wu* \\ School of Electronic and Mechanical Engineering, Guilin University of Electronic Technology, Guilin, \\ 541004, China
}

Keywords: Au80/Sn20; eutectic soldering; FEM; residual stress; strain energy.

\begin{abstract}
After Au80/Sn20 eutectic soldering GaAs chips process, Au80/Sn20 solder joints will have large residual stress and strain because of materials' coefficient of thermal expansion (CTE) mismatch. Large strain deformation will lead to the chip position migration. On the other hand too much stress can make the interface micro cracks and affect the quality and long-term reliability of Au80/Sn20 solder joints. Choosing welding pressure, cooling rate and the thickness of the precast solder pieces as the key process parameters, and designing the L16 (43) orthogonal test table. According to the Au80 / Sn20 eutectic soldering real environment, using finite element analysis software ANSYS to establish the simulation model of Au80 / Sn20 eutectic soldering process. After simulation analysis, it got the maximum residual stress and the strain energy of the solder joint. The primary of the factors is cooling rate, the secondary of the factors is the thickness of the precast solder pieces and pressure is the last by range analysis. The achieved process parameters and forming residual stress and the strain energy of the relationship between solder joints can provide reference and guidance for practical production.
\end{abstract}

\section{Introduction}

In recent years, eutectic Au80/Sn20 is one of best known hard solders having excellent fatigue-resistance and mechanical properties for the assembly of bare chips microwaves components and optoelectronics. Conductive adhesive, Sn63Pb37,Sn96.5/Ag3/Cu0.5 are also commonly used connection mode because of their low processing temperature, the cost of lower and simple process. However, along with the electronic integrated circuit to high density, high reliability, high power and high frequency direction development, their thermal performance, mechanical strength and reliability have got a big challenge. So Au80/Sn20 has been noticed widely for its good thermal conductivity, low resistivity, high mechanical strength and good technological consistency. Especially since the EU has issued a RoHS directive limited the use of leaded solder, and the Au80/Sn20 is the only lead-free solder in $280^{\circ} \mathrm{C} 360^{\circ} \mathrm{C}$ and that makes the Au80/Sn20 used widely in high power and high frequency chip solder welding, photoelectron encapsulation, MEMS and other fields has been widely applied.

Thermal stress and strain produced during heating and cooling and continue to exist after the process end. Wu et al [1] studied the thickness of precast solder pieces, pressure, temperature curve setting, gold-plated layer and atmosphere influence on forming on the mechanical properties of the solder joints by experimental methods. He got the pressure, welding temperature affect the shear strength of solder joints, the atmosphere affecting welding void rate. Hou [2] et al analyzed pressure, the cooling rate gold-plated layer and the peak temperature influence on AuGe eutectic welding, draw a greater influence on the cooling rate on the shear strength of welds. The paper [3] studied the effect of the size of the solder joint especially the height on the solders reliability under many times reflow soldering process, the conclusion is that the smaller size solder have the better performance.

\section{Eutectic welding process}

Au80/Sn20 eutectic welding technology is a low melting point technology. Under the temperature $\left(280^{\circ} \mathrm{C}\right)$, solder Au80/Sn20 appears eutectic fusion phenomenon, the alloy directly 
from liquid to solid, and not through plastic deformation. Au80 / Sn20 eutectic welding principle as shown in figure 1: firstly, reducing the oxygen content of eutectic in furnace through multiple vacuuming and filling nitrogen, fixing substrate, solder and chip by the special fixture. Secondly, to guarantee the molten solder could be fully wetting spreading surface of substrate need a certain pressure. Finally, setting a temperature profile and heating up. As shown in figure 1: the profile preheating stage (Q1), heat preservation stage (Q2), heating stage (Q3), welding stage (Q4) and cooling stage (Q5) as like reflow soldering. However, to prevent the oxidation of the molten solder and get the solder joint performance is usually pump air into vacuum state during welding stage and Au80/Sn20 eutectic soldering is in the same furnace chamber.
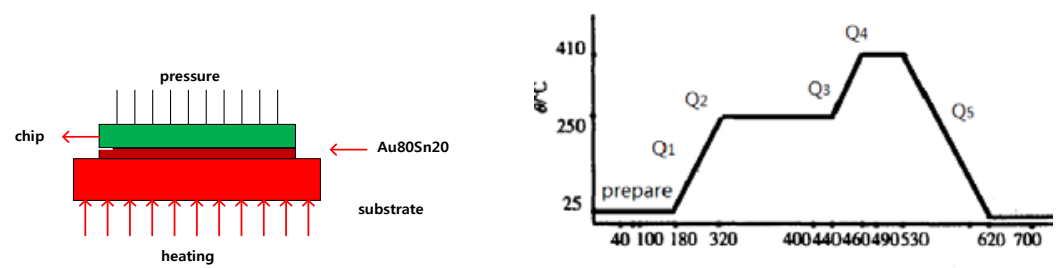

Fig.1:Au80/Sn20 eutectic welding principleFig.2:Au80/Sn20 eutectic welding profile

\section{Finite element simulation}

\section{The physical equations}

The transient heat conduction physical equation of Au80/Sn20 eutectic welding temperature distribution:

$$
\begin{aligned}
& \frac{\partial T}{\partial t}=\alpha_{T}\left(\frac{\partial^{2} T}{\partial x^{2}}+\frac{\partial^{2} T}{\partial y^{2}}+\frac{\partial^{2} T}{\partial z^{2}}\right) \\
& \alpha_{T}=k /\left(\rho c_{p}\right)
\end{aligned}
$$

Where $\mathrm{T}$ is the temperature of electronic component; $\mathrm{t}$ is the soldering time; $\alpha \mathrm{T}$ is the thermal diffusion coefficient; $\mathrm{k}$ is the coefficient of thermal conductivity; $\rho$ is the density of material; $\mathrm{cp}$ is the heat capacity of the materials.

The transient thermal stress physical equation of Au80/Sn20 eutectic welding:

$$
[M]\{\ddot{u}\}+[C]\{\dot{u}\}+[K]\{u\}=\left\{F^{a}\right\}
$$

Where [M], [C], [K] is the mass matrix, damping matrix, stiffness matrix, separately; $\{\ddot{u}\},\{\dot{u}\}$, $\{u\}$ is the acceleration vector, velocity vector, displacement vector, separately; $\left\{F^{a}\right\}$ is outside of the structure load vector.

The convection heat transfer physical equation:

$$
Q_{c}=\frac{0.664 u^{1 / 2} \operatorname{Pr}^{1 / 3} \lambda}{(v L)^{1 / 2}} A\left(T_{w}-T_{f}\right)
$$

Where A is the convective heat transfer area; Tw, Tf is the temperature of component and the temperature of gas (N2); $\mu$ is the velocity of nitrogen; $v$ is the viscosity of the nitrogen; $L$ is the characteristic length of the substrate; $\operatorname{Pr}$ is the Prandtle number; $\lambda$ is the kinematic viscosity coefficient of the gas.

\section{The geometry model}

The dimension of microwaves chip (GaAs) is $4 \mathrm{~mm} * 4 \mathrm{~mm} * 0.1 \mathrm{~mm}$, the precast Au80/Sn20 solder pieces' is $4 \mathrm{~mm} * 4 \mathrm{~mm} * 0.025 \mathrm{~mm}$, the W90/Cu10 substrate is $6 \mathrm{~mm}^{*} 6 \mathrm{~mm}^{*} 0.2 \mathrm{~mm}$. The height of the precast solder pieces range is $25 \mathrm{um} \sim 50 \mathrm{um}$. This is the specific structure of a radio frequency function layer structure. Figure 3 is the finite element model of the overall and the finite element model of precast solder pieces. 


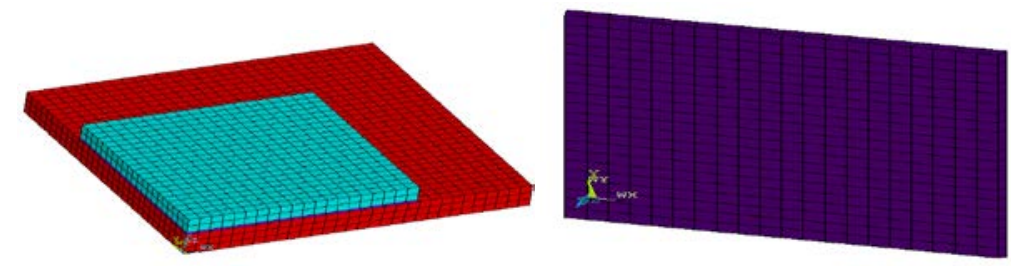

Fig.3: The 3D finite element model of the overall and Au80/Sn20 solder Material Properties

Table1: ANAND model parameters of Au80/Sn20

\begin{tabular}{lllllllll}
$S_{0}(M P a)$ & $Q / R\left(\frac{1}{K}\right)$ & $A\left(\frac{1}{\mathrm{sec}}\right)$ & $\xi$ & $h_{0}(M P a)$ & $m$ & $\hat{s}(M P a)$ & $n$ & $a$ \\
\hline 69.99 & 7578.7 & 93.07 & 11 & 306280 & 0.573 & 466.13 & 0.046 & 1.402 \\
\hline
\end{tabular}

The influence of material properties on the results of numerical simulation is very important. The most critical Au80/Sn20 solder used is ANAND unified viscid-plastic model, it considers the elastic deformation and plastic deformation of solder and creep deformation on the result of solder joints, the specific parameters are shown in table 1[5]. The chip and the heat sink substrate adopt elastic model, the specific material parameters such as table 2.

\section{Load and boundary conditions}

Table2: Material parameters

\begin{tabular}{|c|c|c|c|c|c|c|}
\hline $\begin{array}{l}\text { Materi } \\
\text { al }\end{array}$ & $\begin{array}{l}\mathrm{CTE}(10 \\
\left.{ }^{-6} \mathrm{~K}^{-1}\right)\end{array}$ & $\begin{array}{l}\mathrm{E} \\
(\mathrm{GPa} \\
)\end{array}$ & $v$ & $\begin{array}{l}\text { Dens } \\
\text { ity }(\mathrm{k} \\
\left.\mathrm{g} / \mathrm{m}^{3}\right)\end{array}$ & $\begin{array}{l}\text { Specific } \\
\text { heat(Jkg } \\
\left.{ }^{-1} \mathrm{~K}^{-1}\right)\end{array}$ & $\begin{array}{l}\text { Thermal } \\
\text { conductivity( } \\
\left.\mathrm{Wm}^{-1} \mathrm{~K}^{-1}\right)\end{array}$ \\
\hline GaAs & 7.6 & 83.47 & $\begin{array}{l}0.31 \\
1\end{array}$ & 5320 & 322 & 54 \\
\hline $\begin{array}{l}\text { W10/ } \\
\text { Cu90 }\end{array}$ & 6.5 & 302 & 0.29 & $\begin{array}{l}1700 \\
0\end{array}$ & 152 & 188 \\
\hline $\begin{array}{l}\text { Au80/ } \\
\text { Sn20 }\end{array}$ & 17.5 & 115 & $\begin{array}{l}0.40 \\
6\end{array}$ & $\begin{array}{l}1451 \\
0\end{array}$ & 128 & 315 \\
\hline
\end{tabular}

The Au80/Sn20 eutectic furnace's temperature is room temperature and it was working properly. Assume that the initial stress and strain of chip, solder and substrate is zero. The surface of the chip under certain pressure, the size of the pressure range is 300Pa 2000 Pa. Applying Au80/Sn20 temperature eutectic soldering temperature curve load in the substrate plate under surface, and the highest temperature is $300^{\circ} \mathrm{C}$. Heat convection and thermal radiation is a finite element model boundary conditions, In order to facilitate calculation, the radiation heat transfer is usually converted the heat convection. The undersurface of substrate is fixed constraint, that is $u x=0$, uy $=0$, $\mathrm{uz}=0$.

\section{Design of experiment and simulation}

Selecting Au80/Sn20 welding cooling rate, pressure and the thickness of the precast solder pieces as the key factors and designing the orthogonal test. The concrete level of factors is shown in table 3. Choosing the orthogonal table L16 (43). According to orthogonal test table for simulation analysis, then distill the results data. 
Table3: The select factors and levels orthogonal test

\begin{tabular}{llccc}
\hline Factor & 1 & 2 & 3 & 4 \\
\hline $\begin{array}{c}\text { Pressure (Pa) } \\
\begin{array}{c}\text { Cooling rate } \\
\left({ }^{\circ} \mathrm{C} / \mathrm{s}\right)\end{array}\end{array}$ & 400 & 800 & 1200 & 1600 \\
$\begin{array}{c}\text { Solder } \\
\text { thickness (um) }\end{array}$ & 0.8 & 1 & 1.2 & 1.4 \\
\hline & 20 & 25 & 30 & 35 \\
\hline & $U=\iiint \frac{1}{2}\left(\sigma_{x} \varepsilon_{x}+\sigma_{y} \varepsilon_{y}+\sigma_{z} \varepsilon_{z}+\tau_{x y} \gamma_{x y}+\tau_{x z} \gamma_{x z}+\tau_{y z} \gamma_{y z}\right) d V$
\end{tabular}

The calculation of strain energy: According to the principle of virtual work, for the strain energy of rectangular thin plate shape structure, we can through the type (4) calculation. Where $\left\{\sigma_{x}, \sigma_{y}, \sigma_{z}, \tau_{x y}, \tau_{y z}, \tau_{z x}\right\}$ is the components of stress of precast solder pieces. $\left\{\varepsilon_{x}, \varepsilon_{y}, \varepsilon_{z}, \gamma_{x y}, \gamma_{y z}, \gamma_{z x}\right\}$ is the components of strain of precast solder pieces.

\section{Result and discussion}

Figure 5, figure 6 shows that stress and strain are mainly concentrated in precast solder pieces' angle points and edges, and he stress and strain distribution of middle section is more homogeneous. It may be that the structure factors and heating temperature gradient caused by the large difference. The simulation results have a good consistency with the literature [4].

The figure 4, figure 5 shows that the maximum residual stress of the Au80/Sn20 solder is $10.9 \mathrm{MPa}$, and the maximum residual strain is 1.38e-4.According to GB/T7704-2008, China Electronic Product Reliability and Environmental Testing Research Institute used X-ray stress analyzer for measuring the welding residual stress of gold plated metal with Au80Sn20 after molding and the scope of stress: 4.4 19.2MPa. The measurement results have good consistency with the simulation results, which indicates that the accuracy of the simulation results have certain.
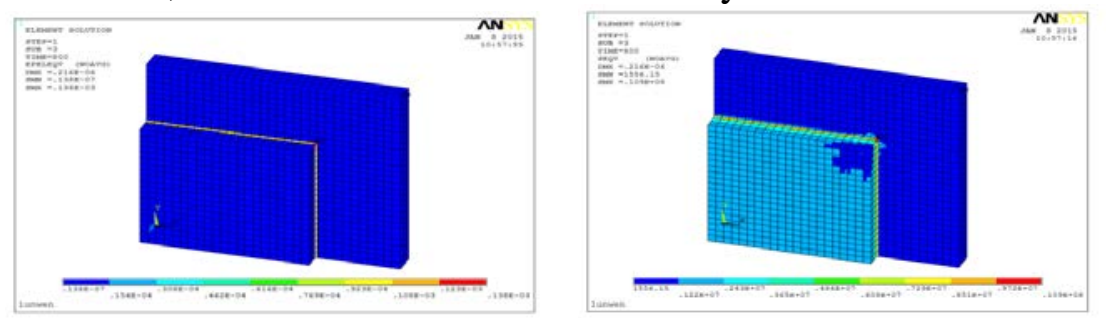

Fig.4: The overall component's stress and strain distribution (pressure $=400 \mathrm{~Pa}$, cooling rate $=0.8$, thickness $=20 \mathrm{um}$ )

The figure 4, figure 5 shows that the maximum residual stress of the Au80/Sn20 solder is $10.9 \mathrm{MPa}$, and the maximum residual strain is 1.38e-4.According to GB/T7704-2008, China Electronic Product Reliability and Environmental Testing Research Institute used X-ray stress analyzer for measuring the welding residual stress of gold plated metal with Au80Sn20 after molding and the scope of stress: 4.4 19.2MPa. The measurement results have good consistency with the simulation results, which indicates that the accuracy of the simulation results have certain.
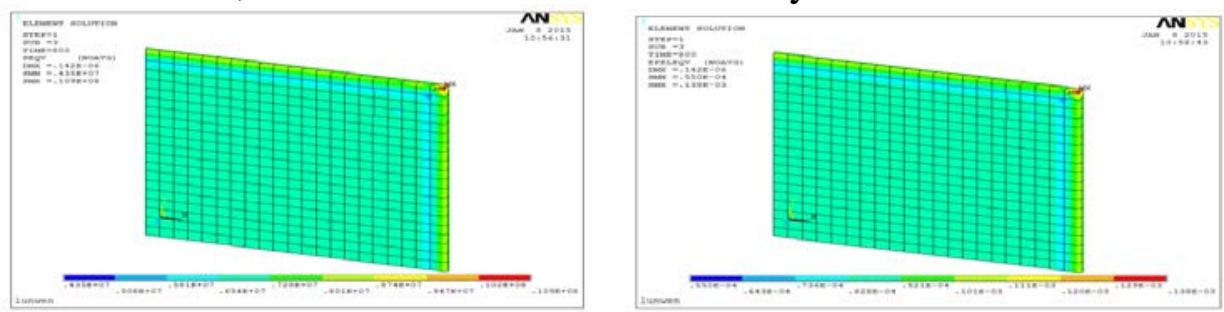

Fig.5: The Au80/Sn20 solder stress and strain distribution (pressure $=400 \mathrm{~Pa}$, cooling rate $=0.8^{\circ} \mathrm{C} / \mathrm{s}$, thickness=20um) 
By the orthogonal experiment result: The minimum residual stress appears when the pressure is $1600 \mathrm{~Pa}$, the cooling rate is $0.8{ }^{\circ} \mathrm{C} / \mathrm{s}$ and the thickness of Au80/Sn20 precast solder pieces is $35 \mathrm{um}$, it is $9.94 \mathrm{MPa}$. However, when the pressure is $800 \mathrm{~Pa}$, the cooling rate is $0.8{ }^{\circ} \mathrm{C} / \mathrm{s}$ and the thickness of Au80/Sn20 precast solder pieces is $25 \mathrm{um}$, the residual strain energy minimum of Au80/Sn20 precast solder pieces is minimum. The interesting is that the biggest residual stress is $10.5 \mathrm{MPa}$, it shows that the residual strain energy have good consistency with the maximum residual stress. So when the strain energy is the minimum, the optimum combination is that the pressure is $800 \mathrm{~Pa}$, the cooling rate is $0.8{ }^{\circ} \mathrm{C} / \mathrm{s}$ and the thickness of Au80/Sn20 precast solder pieces is $25 \mathrm{um}$. The paper [1] aims at the maximum shear strength of the Au80/Sn20 solder joints and it got the shear strength is the maximum when the pressure is $2000 \mathrm{~Pa}$ and the gold-plated layer thickness was $1.5 \mathrm{um}$. The article [6] is that the pressure is 600Pa and the thickness of Au80/Sn20 precast solder pieces is 25.4 um. This may be because the optimization goal and the chip size mismatch.

Table4: The analysis of range of orthogonal experiment results table

\begin{tabular}{|c|c|c|c|c|c|c|}
\hline Factor & \multicolumn{2}{|c|}{ Pressure } & \multicolumn{2}{|c|}{ Cooling rate } & \multicolumn{2}{|c|}{ Solder thickness } \\
\hline Level & Stress & $\begin{array}{l}\text { Strain } \\
\text { energy }\end{array}$ & Stress & $\begin{array}{l}\text { Strain } \\
\text { energy }\end{array}$ & Stress & $\begin{array}{l}\text { Strain } \\
\text { energy }\end{array}$ \\
\hline 1 & 13.45 & $7.04201 \mathrm{e}^{-2}$ & 10.385 & $3.79663 \mathrm{e}^{-2}$ & 14.225 & $4.74456 \mathrm{e}^{-2}$ \\
\hline 2 & 13.475 & $6.86839 e^{-2}$ & 12.65 & $5.60357 \mathrm{e}^{-2}$ & 13.675 & $5.96986 \mathrm{e}^{-2}$ \\
\hline 3 & 13.575 & $6.40704 \mathrm{e}^{-2}$ & 14.65 & $7.54381 \mathrm{e}^{-2}$ & 13.275 & $7.21278 \mathrm{e}^{-2}$ \\
\hline 4 & 13.61 & $6.15821 \mathrm{e}^{-2}$ & 16.425 & $9.45685 \mathrm{e}^{-2}$ & 12.935 & $8.47366 \mathrm{e}^{-2}$ \\
\hline Stress(MPa) & \multicolumn{2}{|c|}{0.16} & \multicolumn{2}{|c|}{6.04} & \multicolumn{2}{|c|}{1.29} \\
\hline Strain energy (uJ ) & \multicolumn{2}{|c|}{$0.88 \mathrm{e}^{-2}$} & \multicolumn{2}{|c|}{$5.66 \mathrm{e}^{-2}$} & \multicolumn{2}{|c|}{$3.73 \mathrm{e}^{-2}$} \\
\hline
\end{tabular}

By means of the orthogonal experiment design and analysis of range, it obtains that the greatest effect Au80/Sn20 solder joint strain energy is the cooling rate, the second is the thickness of prefabricated solder pieces and the pressure is the minimum. The pressure in $400 \sim 1600 \mathrm{~Pa}$ range, with the increase of the pressure, the maximum stress Au80/Sn20 solder joint increase, however, the strain energy reduce. It may be the inconsistent direction of the thermal stress and the pressure caused. The cooling rate within $0.8 \sim 1.4{ }^{\circ} \mathrm{C} / \mathrm{s}$, with the increase of cooling rate, the maximum residual stress and the strain energy increase. This is because the rapid cooling lead to the temperature gradient of precast solder pieces increases rapidly, and the residual thermal stress increase. In thickness of precast solder thickness within the scope of the $20 \sim 35 \mathrm{um}$, with the increase of the thickness of the precast solder pieces, the maximum residual stress reduce, strain energy increase. This is because the precast solder thickness increase lead to the change of the structure and the residual thermal stress reduce, But due to the increase of the deformation volume, the strain energy increase.

\section{Summary}

Au80/Sn20 eutectic process parameter optimization is the key to get the smaller residual stress and strain energy. By means of the orthogonal experiment design and analysis of range, the cooling rate on the influence of residual stress and the strain energy is the largest. This is because the excessive cooling rates lead to uneven heating components and temperature gradient increases, hence the thermal stress and strain energy increase. The thickness of precast solder and the pressure affect lesser. Therefore, in Au80/Sn20 eutectic process, in order to reduce residual stress and the strain energy, reducing the cooling rate is a better choice. 


\section{Acknowledgements}

This work was financially supported by National Defense Basic Scientific Research Project 《**** Layer Multiple Energy Load Theory Research》.

\section{References}

[1] Wu Jian-Hua, Research on chip eutectic technology of thin film substrate. Electronic Component \& Device Applications,10(14), pp.21-25, 2012.

[2] Hou Yi-Xue, Qiao Hai-Ling \& Liao Zhi-Li. Eutectic Solder Technology of Hybrid Circuit Substrate and Package. Electronic \& Packaging,7(8), pp.9-20, 2007.

[3] D.Q. Yu, H. Oppermann, J. Kleff and M. Hutter et al. Interfacial metallurgical reaction between small flip-chip Sn/Au bumps and thin $\mathrm{Au} / \mathrm{TiW}$ metallization under multiple reflow. Scripta Materialia,pp.606-609, 2008.

[4] Fan Lin-Xia. Research on reliability of Au80/Sn20 solder joint for laser diode packages [D]. Tianjin University, pp.37-50,June 2007.

[5] Zhang Guo-Shang. Research on the mechanical properties of Au80/Sn20 solder alloy[D]. Tianjin University, pp.42-44,February 2012.

[6] Jia Yao-Ping. Studies of low voidage vacuum eutectic welding process of the power chip. China Science and Technology Information,pp.125-126, 2013.

[7] Zhang Pei-Xin. The Energy Theory of Structural Mechanics .Shanghai: Shanghai Science and Technology Publishing House, 2010. 